\title{
CORRIGENDUM
}

\section{Functional imaging of neuron-astrocyte interactions in a compartmentalized microfluidic device}

Yandong Gao, Joey Broussard, Amranul Haque, Alexander Revzin and Lin Tian

Microsystems \& Nanoengineering (2016) 2, 16014; doi:10.1038/micronano.2016.14; Published online: 24 March 2016

Correction to: Microsystems \& Nanoengineering (2016) 2, 15045; doi:10.1038/micronano.2015.45; Published online: 29 February 2016

Since the publication of this article, the authors have noticed an error in the author list. Author 'Tian Lin' should be 'Lin Tian'. The authors apologize for any inconvenience it may have caused. 